\title{
Advantages of Additive Technologies Usage in Design of Cooling Channels
}

\section{Karel Raz}

Regional Technological Institute, Faculty of Mechanical Engineering, University of West Bohemia in Pilsen. Univerzitni 22, 30614 Plzen. Czech Republic. E-mail: kraz@rti.zcu.cz

\begin{abstract}
Main aim of this paper is to analyze the thermal behavior of different cooling channels and to describe advantages of manufacturing of a mold with these channels using a 3D printer instead of drilling machines. This work was primarily done by the usage of virtual simulation. Validation of thermal simulations was performed by usage of simple analytical solution. A simple model of molded brick was designed to analyze the cooling time and the temperature distribution in the mold when changing the cross section of the cooling channels. Three types of different rectangular cross-sections and one circular were chosen. All of them have the same area. The cooling channel with circular cross section was positioned closer to the part in next design and influence of this change was analyzed. Last tested configuration is conformal cooling channel with a channel path twice longer. It is obvious, that most suitable configuration of cooling channels is combination of conformal design with rectangular shape as close as possible to plastic part.
\end{abstract}

Keywords: Injection Molding, Cooling, Additive Technologies

\section{Introduction}

The injection molding process is the process that produces plastic parts through the injection and cooling of molten polymers in a mold cavity. In this process, a material load called "shot" is moved by a screw and it enters the cavity through a system of gates and channels where it is going to be formed. It is well known that the configuration of cooling channels can affect directly the final properties of the produced parts.

Cooling channels are tubes in the body of mold through which a cooling liquid (water) is circulated in order to condense the melted material inside the mold. It is necessary to have as uniform temperature during cooling as possible. 3D printing brings new possibilities into the design of cooling channels $[1,2]$.

$3 \mathrm{D}$ printing is manufacturing process of producing $3 \mathrm{D}$ solid objects from a CAD file using additive process. Final product is created by laying down layers of material until the object is finished. Each of these layers can be seen as a horizontal cross-section of the product. $3 \mathrm{D}$ printing of metals enables to produce complex geometry using less material than traditional manufacturing methods. This property is very useful to produce cooling channel in molds. Fig. 1 shows, that cooling is most time consuming process during injection molding. It is necessary to reduce cooling time as much as possible by new design of channels.

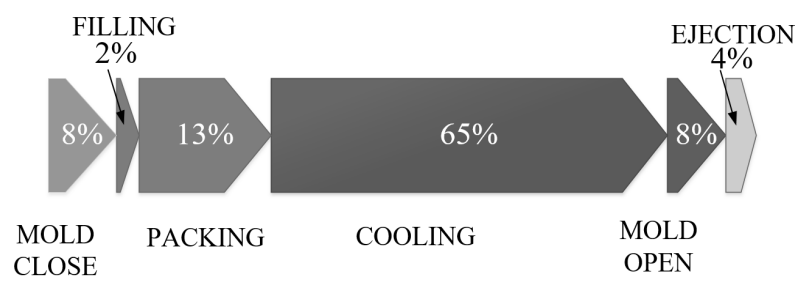

Fig. 1 Times during injection molding

Main aim of this paper is to analyze the thermal behavior of different cooling channels. Considered designs has to be produced by $3 \mathrm{D}$ printer instead of drilling. Performed research is primarily done by the usage of virtual simulation.

Current researches indicates that straight channels configuration manufactured by drilling machines are not the best design for cooling system [3,4]. Analyses of virtual models showed that conformal cooling channel significantly reduced cycle time and improved the quality of the surface. It is well known that reduction in time spent on cooling would drastically increase the production rate and thus reduce costs [5].

Time and quality of the produced part must walk together. Non-uniform cooling is the main cause of warpage after the part is ejected. This can be avoided by designing cooling channels that can involve all sections of the part [6].

An example was made to analyze the influence of the cross section shapes on cooling time and temperature distribution. Considerations, simulations parameters and results of it will be discussed.

\section{Simulation parameters}

Tab. 1 Simulation parameters.

\begin{tabular}{|l|l|}
\hline Injection temperature & $280{ }^{\circ} \mathrm{C}$ \\
\hline Mold initial temperature & $90{ }^{\circ} \mathrm{C}$ \\
\hline Water initial temperature & $15{ }^{\circ} \mathrm{C}$ \\
\hline Volume flow (coolant) & $101 . \mathrm{min}^{-1}$ \\
\hline Simulation time & 120 seconds \\
\hline Type of contact & $\begin{array}{l}\text { Perfect (medium coupling } \\
\text { resolution) }\end{array}$ \\
\hline $\begin{array}{l}\text { Free convection to the } \\
\text { environment }\end{array}$ & Mold wall \\
\hline
\end{tabular}

FEM thermal analysis using NX11 Siemens was used with coupled thermal-flow simulation. The analysis considered transient solution. Each part of the model was meshed individually. Cooling channels were meshed with boundary layer mesh (5 layers) in order to analyze the velocity close to the wall channels. TET4 elements with 1 $\mathrm{mm}$ size were used for channels. TET4 3D mesh with $2 \mathrm{~mm}$ element size was used for the mold and $1 \mathrm{~mm}$ ele- 
ment size was used for the plastic part. The contact between bodies was made with automatic creation $[7,8]$. The simulation parameters are described in the table below.

\section{Cooling channels designs}

A simple model of molded brick was designed to analyze the cooling time and temperature distribution in the mold when changing the cross-section of the cooling channels. Circular shape and three types of rectangular shapes were chosen. All cross-sections have same area

\section{$78.5 \mathrm{~mm}^{2}$.}

The study of the cross section was divided in different configurations. Circular channel has diameter $10 \mathrm{~mm}$. First and second rectangular shape have the same dimensions $10.2 \times 7.8 \mathrm{~mm}$. The only difference between them is that the longer side of the second situation is parallel to the side of the plastic part while the first one has the smaller side parallel to the plastic part. The dimension of the third rectangular shape is $18 \times 4.4 \mathrm{~mm}$ and its longer side is parallel to the plastic part in order to improve the heat exchange. All designs described above have the same centerline position as the circular shape.

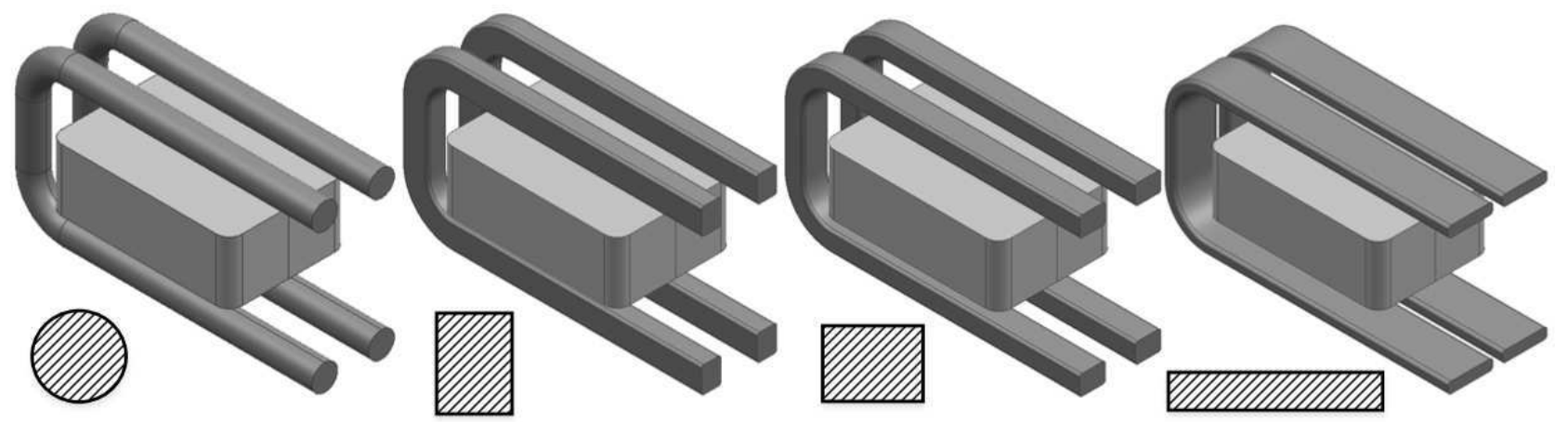

Fig. 2 Circular, rectangular shape 1, 2, 3 and position with respect to plastic part
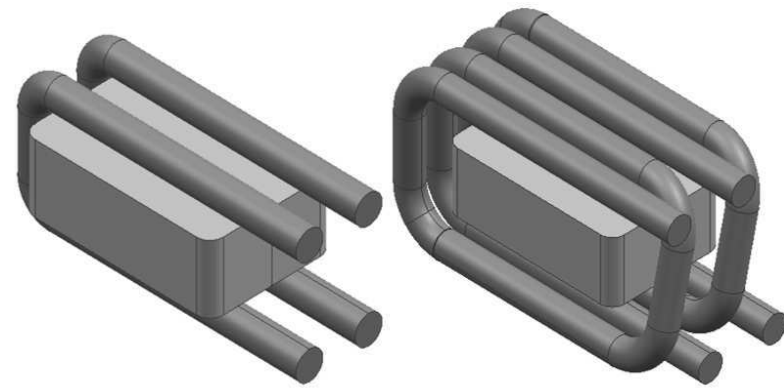

Fig. 3 Closer circular cooling channels and its position with respect to plastic part (left) and conformal circular design
The cooling channel with circular cross section was positioned closer to the part in following step and influence of this change was analyzed (Fig. 3). Before this change, the channel centerline was $15 \mathrm{~mm}$ away from the cavity wall and this distance was reduced to $6.5 \mathrm{~mm}$.

Last tested configuration is conformal cooling channel with a twice longer path as it can be seen in Fig.3. The channel centerline was $15 \mathrm{~mm}$ away from the cavity wall in conformal design. It is possible to produce described designs by additive technologies.

\section{Influence of cooling on mold}

The average nodal temperature of the mold was measured for each design. Four different time steps were compared. The result can be seen in Tab.2.

Tab. 2 Mold nodal average temperature, in ${ }^{\circ} \mathrm{C}$.

\begin{tabular}{|l|l|l|l|l|}
\hline & 12 seconds & 24 seconds & 36 seconds & 108 seconds \\
\hline Circular & 64.87 & 49.97 & 40.27 & 19.76 \\
\hline Rectangular shape 1 & 63.69 & 49.80 & 40.70 & 20.07 \\
\hline Rectangular shape 2 & 62.60 & 47.83 & 38.42 & 19.21 \\
\hline Rectangular shape 3 & 61.45 & 46.95 & 37.67 & 18.79 \\
\hline Closer circular & 64.23 & 49.15 & 40.06 & 19.27 \\
\hline Conformal circular & 53.63 & 39.07 & 30.80 & 17.36 \\
\hline
\end{tabular}

It can be seen that rectangular shape 3 shows the lowest temperature of the mold comparing to other rectangular shapes and circular one. It means that shape 3 is transferring more heat out of the mold. The longest side of the rectangular cross-section must be closer to the plastic part to ensure better cooling effect. Increasing the perimeter (it means usage of rectangular shape 3 for example) is a good way to improve cooling. Heat transfer can be up to
$15 \%$ higher with optimal channels described in this research.

\section{Influence of cooling on plastic part}

The average temperature distribution of part in two different time steps is described in Tab.3. 
Tab. 3 Plastic part average nodal temperature, in ${ }^{\circ} \mathrm{C}$.

\begin{tabular}{|l|l|l|}
\hline & 24 seconds & 108 seconds \\
\hline Circular & 154.41 & 87.25 \\
\hline Rectangular shape 1 & 153.69 & 86.80 \\
\hline Rectangular shape 2 & 153.97 & 86.89 \\
\hline Rectangular shape 3 & 152.92 & 85.95 \\
\hline Closer circular & 146.63 & 85.31 \\
\hline Conformal circular & 138.6 & 81.16 \\
\hline
\end{tabular}

Rectangular shape 3 is resulting in lowest temperature comparing to other rectangular shapes and simple circular one. It means that this cross section is that one that will get to the ejection temperature faster. Therefore, it will have the lowest cooling time and will produce more parts. When the cooling channels are positioned closer to the part, the plastic part will get lower temperature and cooling will be more faster. Conformal cooling configuration is most effective one because of cooling channels are longest.
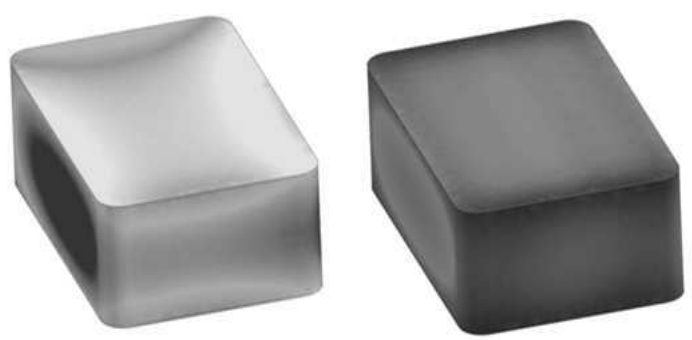

${ }^{\circ} \mathrm{C}$

$$
\begin{array}{lllll}
15 & 17.5 & 20 & 22.5 & 25
\end{array}
$$

Fig. 5 Surface temperature distribution after 108 s for circular (left) and conformal circular (right)

Difference in temperature distribution is obvious in Fig.5, where is showed temperature on external surfaces. It is possible to decrease cooling time by change of mold design with same costs of molding process.
The most suitable configuration of cooling channels is combination of conformal design with rectangular shape 3 as close as possible to plastic part. The application for 3D printer should be used to fabricate molds with cooling channels with optimal cross-section in order to improve production

\section{Validation of contact description}

Main aim of this section is to find the error percentage of the consideration made on the simulation software. It is hard to find correct heat transfer coefficients for considered parts. Perfect contact description was used in analysis because of that. This option is available on the NX Siemens and it can be selected instead of describing the values of thermal coefficients. Perfect contact merges two surfaces making their temperature identical. The Fig. 5 describes the thermal resistance model for the validation.

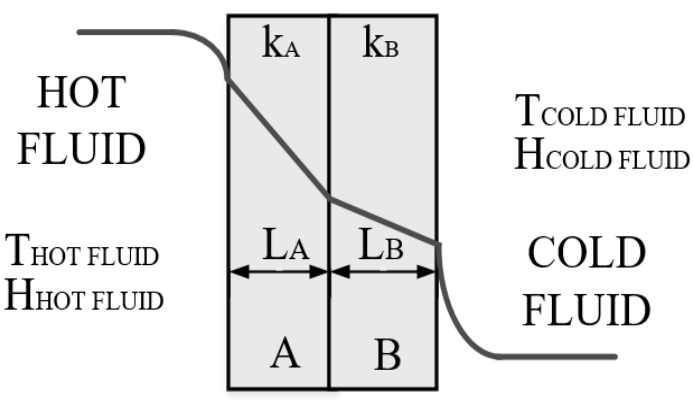

Fig. 5 Equivalent thermal circuit for a series composite
wall

For the validation of the simulation model were used two layers A and B. Parameters used for validation are described in following table. Values are choosen as close to previous simulations as possible.

Tab. 4 Parameters to calculate heat flow.

\begin{tabular}{|l|l|l|l|l|l|l|l|l|l|}
\hline $\mathrm{T}_{\mathrm{A}}$ & $\mathrm{T}_{\mathrm{B}}$ & $\mathrm{L}_{\mathrm{A}}$ & $\mathrm{L}_{\mathrm{B}}$ & $\mathrm{k}_{\mathrm{A}}$ & $\mathrm{k}_{\mathrm{B}}$ & $\mathrm{h}_{\text {hot fluid }}$ & $\mathrm{h}_{\text {cold fluid }}$ & $\begin{array}{l}\mathrm{T}_{\text {hot }} \\
\text { fluid }\end{array}$ & $\begin{array}{l}\mathrm{T}_{\text {cold }} \\
\text { fluid }\end{array}$ \\
\hline $52{ }^{\circ} \mathrm{C}$ & $20^{\circ} \mathrm{C}$ & $15 \mathrm{~mm}$ & $30 \mathrm{~mm}$ & $\begin{array}{l}0.05485 \\
\mathrm{~W} .\left(\mathrm{mm}^{\circ} \mathrm{C}\right)^{-1}\end{array}$ & $\begin{array}{l}0.15425 \\
\mathrm{~W} .\left(\mathrm{mm}^{\circ} \mathrm{C}\right)^{-1}\end{array}$ & $\begin{array}{l}40 \\
\mathrm{~W} .\left(\mathrm{mm}^{\circ} \mathrm{C}\right)^{-1}\end{array}$ & $\begin{array}{l}15 \\
\mathrm{~W} .\left(\mathrm{mm}^{\circ} \mathrm{C}\right)^{-1}\end{array}$ & $72^{\circ} \mathrm{C}$ & $34{ }^{\circ} \mathrm{C}$ \\
\hline
\end{tabular}

Where $T$ is the temperature, $L$ is the thickness, $k$ is the conduction coefficient, $h$ is the convection coefficient and $A$ is the perpendicular area, which respect of the direction of the heat flow. Layers A and B are considering from aluminium and steel, because coefficients for analytical solution are well known. It is possible to calculate the heat flow analytically with the equation (1) described in [9].

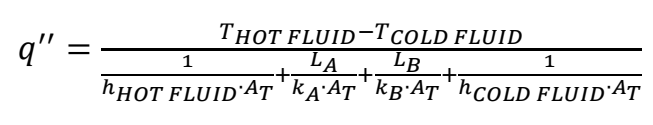

The Fig. 6 shows the model for virtual simulation of heat transfer.

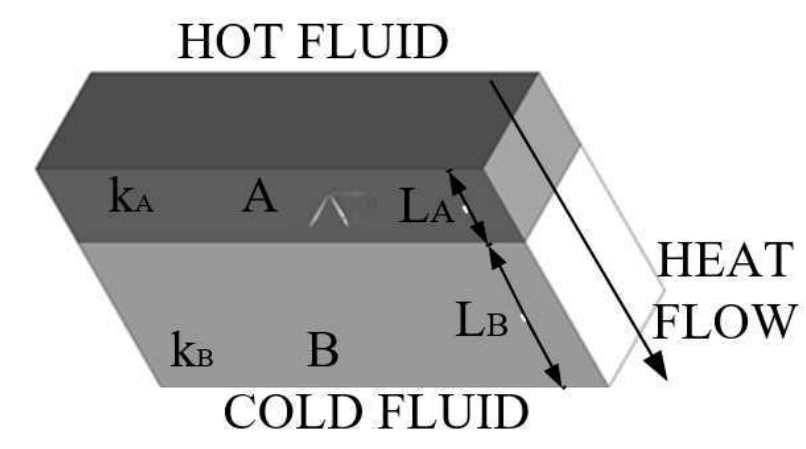

Fig. 6 Perfect contact validation virtual model with two layers 
The Tab.5 shows the comparison between the heat flow analytical and simulation value. The error percentage is not big and the values are close, what means that the thermal analysis using perfect contact is valid.

Tab. 5 Heat flow values, in W. $\mathrm{mm}^{-2}$, and error percentage.

\begin{tabular}{|l|l|l|}
\hline Analytical & Simulation & Error \\
\hline 0.06768 & 0.08111 & $19.8 \%$ \\
\hline
\end{tabular}

\section{Conlcusion}

Some possibilities for impoving the cooling effectiveness on the cooling system for injection molding were showed in this paper. It could be observed that cross sections of the channels with bigger perimeter, but same area improve the cooling effectiveness. Design of the cooling channel closer to the part is a good way to increasing the heat exchange between plastic part, cooling channel and mold and minimizing the cooling time.

The simulations showed also that the increasing of flow rate generated a small difference at the plastic part temperature during time (heat transfer can be considered constant with with described changes of flow). However, it should be analyzed if the increase of the energy spent in the pump for higher flow will be a benefit for the production. Validation of performed analysis was done by analytical solution and comparing of heat flow. This validation was performed on theoretical thermal contact between two plates.

The most suitable configuration of cooling channels is combination of conformal design with rectangular shape 3 as close as possible to plastic part. The application for additive technologies has to be used for production of this mold. Heat transfer can be up to $15 \%$ better with optimalized channels.

For future work, the prototype of the molds discussed in this paper will be tested and the results will be compared with the virtual results presented.

\section{Acknowledgement}

This paper has been prepared under project LO1502 'Development of the Regional Technological Institute' under the auspices of the National Sustainability Programme I of the Ministry of Education of the Czech Republic aimed at supporting research, experimental development and innovation.

\section{References}

[1] RAZ, K., ZAHALKA, M., CHVAL, Z., KUCEROVA, L. (2017). Analysis of Weld Line Influence on Strength of Nylon Parts. In: ManufacturingTechnology, pp. 561-565. ISSN: 12132489

[2] TANG, S.H. (2006). Design and thermal analysis of plastic injection mold, In: Journal of Materials Processing Technology. Switzerland.

[3] ZHENG, R., TANNER,R., FAN,X. (2011). Injection Molding: Integration of Theory and Modeling Methods, Springer-Verlag, Berlin.

[4] HNATKOVA, E., SANETRIK, D., PATA, V., HAUSNEROVA, B., DVORAK, Z., (2016). Mold Surface Analysis after Injection Molding of Highly Filled Polymeric Compounds, In: Manufacturing Technology, Vol. 16, pp. 86-90, ISSN 1213-2489.

[5] COP. J., FOJTL, L., BILEK, O., PATA, V., (2016). Influence of Finishing Operations and Melt Flow Index on Surface Quality of Injection Molded Parts, In: Manufacturing Technology, Vol. 16, pp. 336-338, ISSN 1213-2489.

[6] RUSNAKOVA, S., CAPKA, A., FOJTL, L., ZALUDEK, M., RUSNAK, V., (2016). Technology and Mold Design for Production of Hollow Carbon Composite Parts, In: Manufacturing Technology, Vol. 16, pp. 799-804, ISSN 1213-2489.

[7] FABIAN, M., BOSLAI, R., IZOL. P., JANEKOVA, J., FABIANOVA, J., FEDORKO, G., BOZEK, P., (2015). Use of Parametric 3D Modeling. Tying Parameter Values to Spreadsheets at Designing Molds for Plastic Injection, In: Manufacturing Technology, Vol. 16, pp. 24-31, ISSN 1213-2489.

[8] NHUYEN VO, T., SEIDL, M., (2016). Evaluation of Applicability of Unconventional Cooling Method in Injection Mould, In: Manufacturing Technology, Vol. 16, pp. 220-225, ISSN 1213-2489.

[9] INCROPERA, F.P., DEWITT, D.P., BERGMAN, T.L., LAVINE, A.S. (2011). Fundamentals of heat and mass transfer 7 th edition. USA: John Wiley \& sons. 